


PUCPR

\title{
Primeiro registro de águia-pescadora (Pandion haliaetus, Linnaeus, 1758) no estuário de Iguape - Ilha Comprida
}

\author{
First record of Pandion haliaetus (Linnaeus, 1758) in the \\ Iguape - Ilha Comprida estuary
}

Edison Barbieri $^{[\mathrm{al}}$, Celso Alberto Gonçalves ${ }^{[\mathrm{b}]}$

[a] Doutor em Oceanografia (Oceanografia Biológica) pela Universidade de São Paulo (USP), pesquisador do Instituto de Pesca (APTA - SAASP), Cananeia, SP, Brasil, e-mail: edisonbarbieri@yahoo.com.br

[b] Coordenadoria de Defesa Agropecuária/Secretaria de Agricultura e Abastecimento do Estado de São Paulo, Campinas, SP Brasil, e-mail: celago@terra.com.br

\section{Resumo}

A águia-pescadora é uma ave de grande porte, com hábito alimentar baseado, principalmente, na captura de peixes. Trata-se de uma espécie pertencente à Família Pandionidae, Ordem Falconiformes. É uma ave migratória da região Norte do Continente Americano, chegando ao extremo sul do continente. Publicações anteriores a respeito da avifauna do estuário de Iguape - Ilha Comprida não fazem menção à presença da águia-pescadora na área. Dentro deste contexto, faz-se importante descrever novos registros de sua ocorrência no Estado de São Paulo. Durante os trabalhos de amostragem da avifauna, desenvolvidos

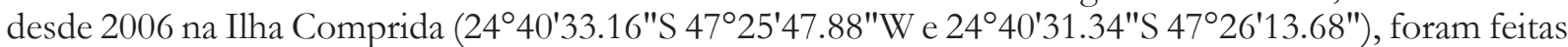
avistagens de $P$. haliaetus em duas oportunidades, ambas no mês de abril de 2009, sobrevoando o Mar Pequeno e a margem da Lagoa da Ilha.

Palavras-chave: Pandion haliaetus. Falconiformes. Estuary. Iguape. Ilha Comprida.

\section{Abstract}

First record of Pandion haliaetus (Linnaeus, 1758) in the Iguape - Ilha Comprida estuary. Pandion haliaetus is a huge bird with alimentary habits based mainly upon fishing. Such species belongs to the Pandionidae Family, Falconiformes Order. It is a migratory bird from the northern region of North America that flies southwards. Former 
publications concerning the birds of Iguape - Ilha Comprida estuary did not mention the presence of this eagle in the region. Thus it is important that forthcoming appearances be recorded. Throughout the bird-sample selection stage, made since 2009 at Iguape - Ilha Comprida estuary $\left(24^{\circ} 40^{\prime} 33.16^{\prime \prime} \mathrm{S} 47^{\circ} 25^{\prime} 47.88^{\prime \prime} \mathrm{W}\right.$ and $24^{\circ} 40^{\prime} 31.34^{\prime \prime} \mathrm{S}$ $\left.47^{\circ} 26^{\prime} 13.68^{\prime \prime}\right)$ - $200 \mathrm{~km}$ from São Paulo -, the bird was seen twice: in April, flying over "O mar pequeno" and at Lagoa da Ilha.

Keywords: Pandion haliaetus. Falconiformes. Estuary. Iguape. Ilha comprida.

\section{Introduçáo}

Pandion haliaetus é uma espécie de ave de rapina de grande porte, com cerca de $57 \mathrm{~cm}$ (em média, os machos atingem $55 \mathrm{~cm}$ e as fêmeas, $63 \mathrm{~cm}$ ) de comprimento (1). A cabeça e partes inferiores são brancas; as partes superiores do corpo, pardo-anegradas; asas longas e estreitas, com mancha negra; penas nucais eriçadas e cauda curta. As patas são cinzento-azuladas, apresentando um bico forte e bem adaptado aos seus hábitos alimentares, baseados, principalmente, na captura de peixes; esporadicamente, caça pequenos vertebrados (roedores e aves) (2).

Trata-se de uma espécie pertencente à familia Pandionidae, ordem dos Falconiformes. É uma ave migratória da região norte do Continente Americano, chegando ao extremo sul da América do Sul. Entretanto, ocorre um pouco por todo o mundo, desde a América do Norte à Austrália, passando pela Europa, por Cabo Verde e peloJapão (1). A população mundial estimada é de cerca de 30 mil casais, sendo a maioria nidificante na América do Norte, daímigrando para a Argentina e Chile $(1,3,4)$, com distribuição isolada em grande parte do Brasil (5). No fim do verão, as águias-pescadoras deixam a região onde se reproduzem e partem para o sul, passando o inverno em zonas tropicais. Mas, na primavera seguinte, cada casal vem procriar exatamente no mesmo lugar. Normalmente é avistada em regiões com grandes extensões de água (2). Indivíduos adultos, no período de descanso reprodutivo, podem ser vistos fora da área de reprodução, fugindo do inverno setentrional. Já os jovens, ainda incapazes de reproduzir-se, podem ser avistados durante todos os meses do ano $(2,5)$. Apesar de ser uma das aves mais estudadas na sua área de reprodução, pouco se conhece a respeito de sua ecologia nas áreas de invernada $(1,5,6,7)$.

Esta espécie nidifica quase sempre perto de água. Captura peixes de água doce, salgada ou salobra, o que lhe permite frequentar estuários, barragens, cursos de água de caudal lento e, por vezes, a orla costeira (2). Normalmente, nidifica em árvores, mas na zona mediterrânea na Europa sempre foi mais comum nidificar junto à costa, nas falésias escarpadas ou em pequenas ilhas rochosas.

Trata-se de uma espécie de hábitos muito solitários, embora haja registros de ocorrências de bandos, mais ou menos dispersos (5). Nas zonas de pesca, normalmente bastante afastadas do ninho, toleram a presença de outros indivíduos, chegando a registar-se uma concentração de 25 indivíduos (8). Geralmente, a águia-pescadora é silenciosa. Apenas na época de reprodução se verifica uma variedade de chamamentos e assobios na zona de nidificação (9).

\section{Material e métodos}

Censo populacional de aves migratórias, como parte do monitoramento da influenza aviária, vem sendo feito desde junho de 2008 na ARIE do Guará, na Ilha Comprida, a $200 \mathrm{~km}$ da cidade de São Paulo. O trabalho se desenvolve durante a maré baixa, melhor período para acesso dos pesquisadores aos locais escolhidos, por meio de contagem direta, segundo a metodologia descrita por Bibby et al. (10), em que o observador, a partir de um ponto fixo, e com o auxílio de luneta Baush \& Lomb $^{\circledR}(20$ x 60) e binóculos (10 x 50 e 20 x 90 x 180), realiza contagem individual da espécie. Durante este estudo foram feitas avistagens de $P$. haliaetus, a qual foi filmada e fotografada. Essa mesma metodologia foi utilizada em Cubatão, SP, por Olmos e Silva e Silva (11).

\section{Resultados e discussáo}

Foram avistadas águias-pescadoras, em duas oportunidades, no mês de abril de 2009, sobrevoando a Lagoa da Ilha e o Mar pequeno de Iguape - Ilha 
Comprida (Figura 1). Em ambas as ocasiões, nas coordenadas $24^{\circ} 40^{\prime} 33.16^{\prime \prime} \mathrm{S} \quad 47^{\circ} 25^{\prime} 47.88^{\prime \prime W}$ e $24^{\circ} 40^{\prime} 31.34^{\prime \prime S} 47^{\circ} 26^{\prime} 13.68^{\prime \prime}$, foram avistados dois indivíduos da espécie em apreço, que se encontravam pescando.

P. haliaetus é considerada uma visitante rara do litoral sul de São Paulo, com nenhuma citação para a área do estuário de Iguape - Ilha Comprida, e nem para a recém-criada ARIE do Guará. Além de estudos no mangue, da cidade de São Vicente (5), existem registros esporádicos para outras regiões, como, por exemplo, no trabalho de Luederwaldt (12), para o município de Santos, e de Olmos (13) para o município de Cubatão.

Publicações a respeito das aves da praia da Ilha Comprida (14) não fazem menção à presença da águia-pescadora na área. Somente em outra região próxima, no estuário de São Vicente, Silva e Silva \& Olmos (5) estudaram a ecologia dessa espécie durante o período de invernada. Dentro deste contexto, faz-se importante descrever novos registros da ocorrência de $P$. haliaetus para o litoral sul do Estado de São Paulo.

Os trabalhos na região do estuário de Iguape - Ilha Comprida continuam sendo desenvolvidos, buscando registrar novas ocorrências da águia-pescadora e de outras aves pouco conhecidas. Ressalta-se a importância de novos registros e acompanhamento mais detalhado da espécie, que permitam evidenciar sua distribuição, características ecológicas e comportamentais nas áreas que ela ocupa durante o período migratório.

\section{Agradecimentos}

Agradecemos ao Instituto de Pesca da Secretaria da Agricultura e Abastecimento do Governo do Estado de São Paulo, pelo precioso apoio dado para que este trabalho tenha sido executado.

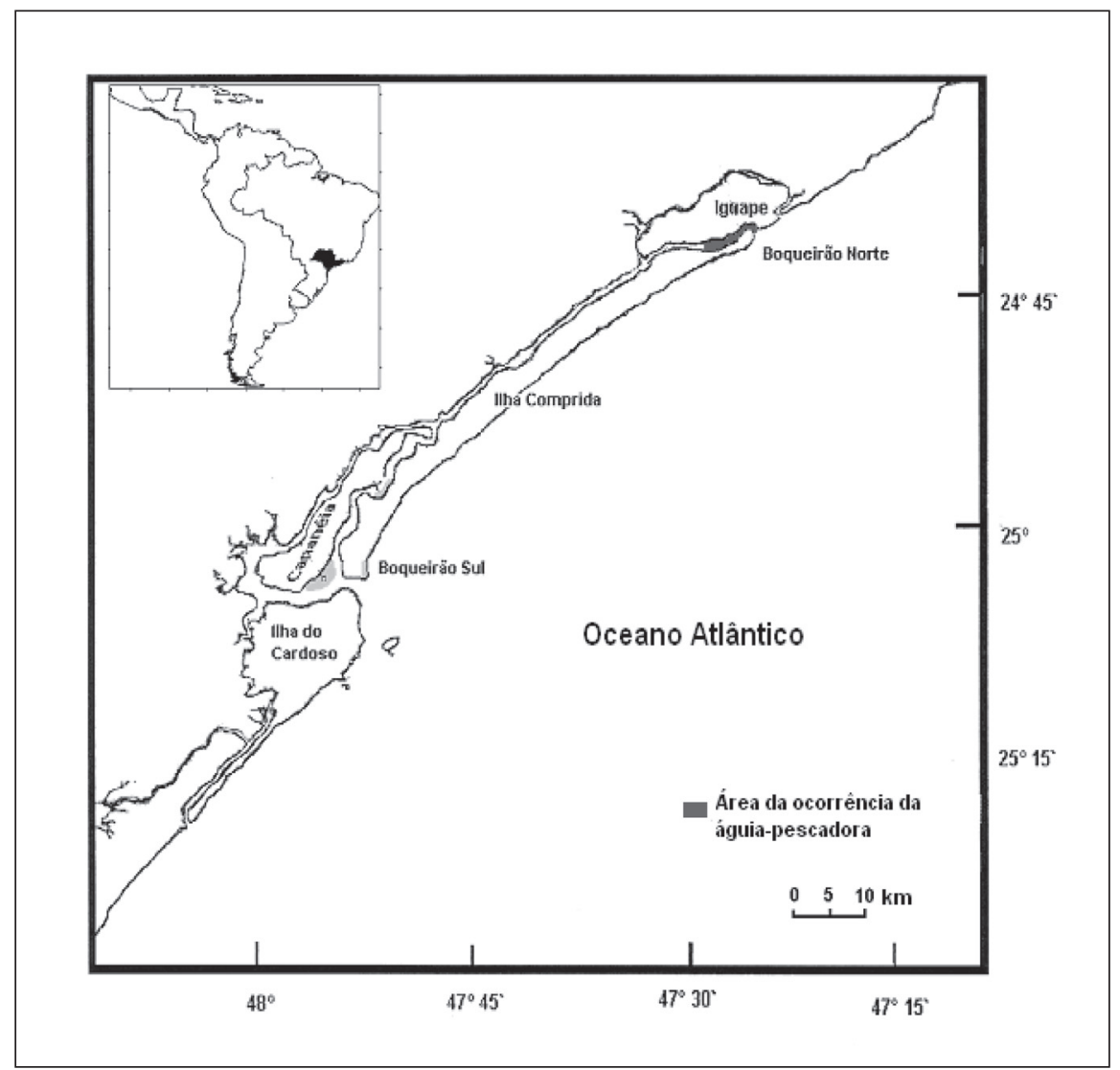

Figura 1 - Localização do estuário de Iguape - Ilha Comprida com a área de estudo assinalada em vermelho 


\section{Referências}

1. Poole AF. Ospreys: a natural and unnatural history. Cambridge: Cambridge Univ. Press; 1989.

2. Sick H. Ornitologia brasileira. 2a ed. Rio de Janeiro: Nova Fronteira; 1997.

3. Del Hoyo J, Elliott A, Sargatal, J. (Ed.). Handbook of the birds of the world. New world vultures to Guineafowl. Barcelona: Lynx; 1994.

4. Martell MS, Henny CH, Nye PE, Solensky MJ. Fall migration routes, timing, and wintering sites of North American Ospreys as determined by satellite telemetry. Condor. 2001;103:715-24.

5. Silva e Silva RE, Olmos F. Osprey ecology in the mangroves of southeastern Brazil. J. Raptor Res. 2002;36(4):328-31.

6. Saggese MD, Lucca ER de. Presencia del Aguila Pescadora (Pandion haliaetus) en Argentina y Uruguay. Hornero. 1996;14:44-9.

7. Teixeira EC, Costa ES, Petry MV. Primeiro registro de águia-pescadora (Pandion haliaetus, Linnaeus, 1758) no parque estadual de Itapuã, Viamão, RS. Biodiversidade Pampeana. 2005;3:24-8.

8. Poole AF, Agler B. Recoveries of Ospreys banded in the United States, 1914-84. Journal of Wildlife Management. 1987;51:148-55.
9. Prevost YA. The wintering ecology of Ospreys in Senegambia. Ph.D. [dissertation]. Edinburgh: University of Edinburgh, Scotland; 1982.

10. Bibby JC, Burgues ND, Hill DA. Bird census techniques. London: Academic Press; 1992.

11. Olmos F, Silva e Silva RE. The avifauna of a Southeastern Brazilian mangrove swamp. International Journal of Ornithology. 2001;4(3/4):135-205.

12. Luederwaldt H. Os manguezais de Santos. Revista do Museu Paulista. 1919;11:310-409.

13. Olmos F. A avifauna da baixada do pólo industrial de Cubatão. Revista Brasileira de Biologia. 1989;49:373-9.

14. Barbieri E, Paes ET. Aves da praia da Ilha Comprida (estado de São Paulo, Brasil): uma análise multivariada. Biota Neotropica. 2008;8(3). [acesso em 28 nov. 2009]. Disponivel em: http:/ / www.biotaneotropica. org.br/v8n3/pt/abstract?article+bn00408032008.

Recebido: 15/07/2009

Received: 07/15/2009

Aprovado: 23/11/2009

Approved: 11/23/2009 